\title{
Debility, dependency and dread: On the conceptual and evidentiary dimensions of psychological torture ${ }^{1}$
}

\author{
Ergun Cakal, LLM*
}

\section{Key points of interest:}

- Psychological torture is prohibited by international law, but is illdefined and regularly interpreted as not amounting to torture. Mental suffering needs to be clarified and expanded upon as part of the definition of torture.

- Psychological torture is complex and lacks appropriate acknowledgement in evidence-based fora.

\section{Abstract: \\ Background: Psychological torture is deployed to break and obliterate human resistance, spirit and personality, but it is rarely afforded sufficient attention. Deficiencies in conceptualising, documenting and adjudicating non-physical torture mean that it is frequently left undetected and uncontested by the public, media and the courts, bolstering impunity for}

^) Legal Advisor, DIGNITY - Danish Institute Against Torture.

1 This review has significantly benefited from an ongoing REDRESS-DIGNITY collaboration on the topic. Whilst particular appreciation is owed to REDRESS, any errors and views remain the author's own. The title is a reference to Farber, Harlow \& West (1957).

Correspondence to: erca@dignityinstitute.dk its perpetrators. A review of the current literature to map conceptual and evidentiary shortcomings from an inter-disciplinary perspective is therefore warranted. Method: The relevant texts were identified through a systematic full-text search of databases, namely HeinOnline, HUDOC, UNODS and DIGNITY's Documentation Centre, with the keywords 'psychological torture', 'mental pain and suffering', 'severity', 'humiliation', 'interrogation techniques', and 'torture methods'. The identified texts, limited to English-language journal articles, NGO reports, court-cases and UN documents from 1950 to date, were then selected for relevance pertaining to conceptual, evidentiary, technological and ethical critique provided therein. Results/Discussion: Evidential invisibility, subjectivity of the suffering, and perceived technological control are the primary ways in which psychological torture methods are designed, and how they manage to evade prosecution and consequently be perpetuated.

Cognisant of the need for further research, pertinent questions highlighting the need to develop approaches, sharpen standards and use a medical/psychological/legal interdisciplinary approach are suggested.

\section{Definitions and Concepts}

Whilst it is important to view torture in its totality and to not disproportionately focus 
on certain methods to the exclusion of others (see Ginbar, 2017, p. 305), there exists clear definitional and conceptual challenges with respect to otherwise headline-grabbing examples of psychological torture, e.g. 'enhanced interrogation techniques'. This section will broadly outline the main conceptual approaches that have been or may be used to define and conceptualise psychological torture.

\section{Methods of torture and the mind and body dichotomy}

Difficulties in adequately defining torture are magnified when it comes to psychological torture. As the physical and psychological may be viewed as two sides of the same coin, conceptually delineating between the two poses a difficulty in itself, as we straddle the mind/body dichotomy. According to Sveaass, the psychological impact of powerlessness, fear and uncertainty for any victim of torture means that 'there is no such thing as physical torture "by itself"' (2008, pp. 313-314). In other words, physical methods of torture also have strong psychological effects on a victim, and vice-versa. Rape is an oft-cited example here as, although often involving a physical act, its objective is a psychological one to 'punish, intimidate and humiliate' (see Raquel Martí de Mejía v. Perú, 1996). Providing an additional distinction, PérezSales differentiates between two categories within psychological torture, namely between pure psychological techniques (e.g. humiliation, threats) and attacks on the self through attacks on bodily functions (e.g. exhaustion, sleep deprivation) (PérezSales, 2017, p. 9). For present purposes, psychological effects of torture (e.g. anxiety, depression, PTSD) will be distinguished from psychological methods (both targeted at the body, e.g. exhaustion, and 'pure,' e.g. threats), with the latter being the focus of this review.

Terminology used to describe, dismissively or otherwise, the mental suffering as produced by such methods reflect these intersections. Some notions, such as 'evidence-free torture', emphasise the invisibility of the torture whether inflicted through physical means or not. Terms used in the literature include but are not limited to: 'non-physical torture'; 'white torture'; 'invisible torture'; 'no-touch torture'; 'clean torture'; 'evidence-free torture'; 'hands-off torture'; 'mental torture'; 'torture-lite', and 'psychological torture'.

Sveaass points out that 'it may be possible to describe extremely painful situations where no direct or obvious physical pain is inflicted' (2008, p. 315). For these situations, the label of 'psychological torture' remains apt given that 'the brutality of psychological torture is very much based on what we know of human psychological function ['personal agency, values, emotions, hope, relationships, and trust'], on information and knowledge developed within the realm of psychology' (Sveaass, 2008, p. 316). As the methods with which this review concerns itself target an individual's psychological integrity based on psychological or pseudo-psychological concepts, the term 'psychological torture' will be used throughout this review. Notwithstanding this, the pedagogical nature of this choice must be borne in mind.

\section{Definitional elements}

While international and regional human rights frameworks recognise that the use of psychological methods in and of themselves can constitute torture (as one need only refer to the inclusion of 'mental pain or suffering' under Article 1 of the Convention against Torture (UNCAT)), there is a need 
to produce more workable understandings. It is notable to find that its drafters did not discuss at any length the meaning of 'mental pain or suffering' but some agreed on the difficulties therein (Nowak \& McArthur, 2008, p. 38). Nowak points to the travaux preparatoires in arguing against any notion that the 'drafters intended a narrow interpretation that would exclude conduct as intentional deprivation of food, water, and medical treatment from the definition of torture' (2006, p. 819). While strict categorisations of forms of torture are avoided, it is clear in most jurisdictions that some psychological forms have been accepted as constituting torture or inhuman and degrading treatment or punishment.

Beyond a handful of cases, there remains a superficiality to judicial reasoning which warrants further dialogue with non-legal understandings here. Surveying relevant jurisprudence, Crampton proposes the following criteria as being useful, but not definitive, indicators of psychological torture: i. actions that prevent the detainee from maintaining stable mental health (i.e. forced absorption); ii. significance of the psychological maltreatment; iii. design and planning of the torture; and, iv. the perpetrator's focus on affective bonds to pressure the victim (2013). Similarly, another set of criteria entails: 'i. the relationship pattern between torture and tortured; ii. circumstances of the torturing system (political persecution, ethnic cleansing, law enforcement procedure); iii. Whether techniques target identity; iv. the severity of each experience from both an objective and subjective point of view' (Pérez-Sales, 2017, p. 4).

Notwithstanding its breadth, a preliminary review of international jurisprudence reveals that international law does not provide a uniform approach to methods of psychological torture. It is beyond the scope of this review to further outline the definitional dynamics (interpretative variations, gaps, and limitations) with respect to psychological methods of torture in international law. What is clear is that, with the exception of the UN Special Rapporteur on Torture (UNSRT), there is a tendency, where specific conclusions have been reached by certain bodies, to fix a high threshold for psychological torture violations. It suffices to say, however, that it remains unclear why some factual matrices are found to attract stronger criticism than others, and the inconsistency which reigns with respect to when exactly these bodies specifically condemn a psychological method as torture appears to thwart any meaningful analysis.

\section{Categorisation and typology}

Another approach in striving for conceptual clarity, amidst such ambiguities, has been through categorisation (or an extensional definition), which involves providing a detailed list of techniques known to not leave physical marks. Rejali provides four categories with which to conceptualise such techniques including: i. positional torture, ii. exercising to exhaustion, iii. restraint torture, and iv. beatings (2007). Admittedly, these are also known to leave physical marks such as bruises and nerve damage. Ojeda, defining the phenomenon as 'the intentional infliction of suffering without resorting to direct physical violence', provides a relatively detailed starting point here in his 13 categories:

isolation (including complete or semisolitary confinement); psychological debilitation (deprivation of basic needs, forced physical exertion); spatial disorientation (small, dark cells); temporal disorientation (denial 
of natural light, erratic scheduling of activities); sensory disorientation (inducing perceptions of sensory failure, narcosis or hypnosis); sensory deprivation (hooding, blindfolding, darkness, sound proofing etc.); sensory assault (overstimulation) (bright lights, loud noise/music); induced desperation (arbitrary arrest, indefinite detention, random punishment, forced feeding, implanting sense of guilt or abandonment); threats (to self or others, mock executions, forced witnessing of torture); feral treatment (forced nakedness, denial of personal hygiene, overcrowding, forced interaction, bestialism, incest); sexual humiliation (forcing victim to witness or partake in sexual behaviour); desecration (forcing victims to witness or partake in violating religious practices (irreverances, blasphemy, profanity, defilement, sacrilege); pharmacological manipulation (nontherapeutic use of drugs or placebos).

(Ojeda, 2008, pp. 2-3)

A similar categorisation is found in Behan's work:

disruption of daily rhythms and routines (night interrogation, disruption of sleep and biorhythms, early morning arrest, manipulating diet, sleep patterns, removal of all comfort items); isolation and sensory deprivation (solitary confinement, eliminating lights, sounds, odors, hooding); monopolisation of perception (constant bright cell, physical isolation, barren environment, restricted movement, monotonous food, sensory overload, interrogation in non-standard locations); induced debilitation; exhaustion (starvation, sleep deprivation, prolonged constraint, interrogation); threats (against self and/or family members of death, nonrepatriation, endless isolation and interrogation, vague threats); lies and deception (re evidence against detainee, use of falsified documents or reports); occasional indulgences; demonstrating omnipotence and omniscience; degradation (use of foul language, preliminary humiliation, confinement, denial of personal hygiene, filthy environment, denial of privacy, stripping, removal of clothing); enforcing trivial demands (forced writing, enforcement of extremely detailed rules); heightened suggestibility, hypnosis and narcosis; self-induced physical pain (forced sitting on edge of chair of stool, forced upright kneeling and standing, stress positions); physical abuse (waterboarding, manhandling, mild physical contact such as grabbing, poking, pushing); exploitation of phobias (individual or religious phobias, such as dogs); sexual humiliation (forced stripping etc.) (Behan as quoted in Ojeda, 2008, p. 120)

Unless explicitly emphasised that they are non-exhaustive, the patent danger with such categorisation, inter alia, is it becoming restrictive. As Pictet observed in his commentary to the Geneva Conventions as early as 1958 :

However great the care taken in drawing up a list of all the various forms of infliction, it would never be possible to catch up with the imagination of future torturers who wished to satisfy their bestial instincts; and the more specific and complete a list tries to be, the more restrictive it becomes. (Pictet, 1958, p. 204) The Human Rights Committee ('HRC') adopts the same position in saying that it is 
not 'necessary to draw up a list of prohibited acts or to establish sharp distinctions between the different kinds of punishment or treatment; the distinctions depend on the nature, purpose and severity of the treatment applied' (Human Rights Committee, 1992, $\$ 4)$. This rings especially true if we are to accept the assertion, by one account, that military technology is a decade or two more advanced than that of clinical or academic research (Pérez-Sales, 2017, p. 331).

A narrow definition embracing categorisation, or enumeration, of prohibited acts of psychological torture has been adopted by the United States of America. In domestically implementing the UNCAT, the definition adopted by the United States' federal government presents an interesting case study. It refers to psychological torture as the:

...mental pain or suffering refers to prolonged mental harm caused by or resulting from: (1) the intentional infliction or threatened infliction of severe physical pain or suffering; (2) the administration or application, or threatened administration or application, of mind altering substances or other procedures calculated to disrupt profoundly the senses or the personality; (3) the threat of imminent death; or (4) the threat that another person will imminently be subject to death, severe physical pain or suffering, or the administration or application of mind altering substances or other procedures calculated to disrupt profoundly the senses or personality. (18 U.S.C. $\$ 2340(2)(B)$ )

There have been two main criticisms made against this definition: that enumerating the actions unduly (to threats of imminent death for instance) narrows the understanding of psychological torture, and that it requires prolonged mental harm, a requirement not found in the UNCAT. The latter point was explicitly made by the Committee against Torture (Conclusions and Recommendations: USA, 2006; hereinafter 'CAT').

\section{Conceptions and their contestations: The legal} versus the non-legal

The ruling of whether a particular act or omission constitutes torture is ultimately a judicial one. It is, however, inevitably informed by medical understandings due to the anatomical and psychological conceptualisations of pain. The dominance of blindly legal conceptualisations of torture has been contested for being devoid of this necessary non-legal perspective, for its opaque focus on severity, bias towards the physical, and its Euro-centrism. A number of experts, namely Pérez-Sales, Sveaass and Başoğlu, have argued for a better-informed definition which can help instigate a more scientific understanding of particularly psychological torture. Başoğlu, to reproduce one argument, explains that 'a legal understanding of torture provides protection from torture to the extent that it comes closer to its psychological formulation' (2017, p. 492) and that what is needed is a 'broader definition of torture based on scientific formulations of traumatic stress and empirical evidence rather than on vague distinctions ... that are open to endless and inconclusive debate and, most important, potential abuse' (2017, p. 397).

Sveaass understands psychological torture to be 'the process by which psychological pain is transformed into humiliation and dehumanisation, where the essence of being human - namely personal agency, values, emotions, hope, relationships, and trust - is under attack' (2008, p. 304; see also Sveaass, 1994, p. 43). Pérez-Sales 
also attempts to posit a workable definition as being 'the use of techniques of cognitive, emotional or sensory attacks that target the conscious mind and cause psychological suffering, damage and/or identity breakdown in most subjects subjected to them; such techniques may be used alone or together with other techniques to produce a cumulative effect' $(2017$, p. 8$)$.

The disconnect between the legal and non-legal conceptualisations coupled with the dominance of the former clearly presents a problem for the advancement of our understanding of torture generally, and perhaps an even greater hindrance with respect to psychological torture. The minor role given to dignity and humiliation (linked to self and identity) which feature more prominently in nonlegal understandings is problematic when compared to 'pain-producing techniques' in legal understandings (Pérez-Sales, 2017, p. 262). As shall be discussed later, severity has also proven a challenge for legal minds.

\section{Practices and perpetuation of psychological methods}

This section will explore how psychological methods are designed, enabled and perpetuated under the guise of science and lawfulness. The conceptual argument persists as we draw on 'lawful sanctions', 'intentionality' and the difficulties with respect to distinguishing between torture and cruel, inhuman and degrading treatment (CIDT).

\section{Scientific complicity: The 'benevolence' of technology}

The scientific milieu out of which these methods have sprung is also of import to understanding the phenomenon. Technology, be it in the use of techniques, knowledge or personnel, has been used by state actors to act as an illusion of control purportedly safeguarding the process from breaching the pain threshold.

This was recognised as early as 1978 in the case of Ireland v. the United Kingdom, where in his dissenting opinion, Judge Evrigenis, calling the majority out on their reasoning, found that torture in the case was:

... based on methods of inflicting suffering which have already been overtaken by the ingenuity of modern techniques of oppression. Torture no longer presupposes violence, a notion to which the judgment refers expressly and generically. Torture can be practisedand indeed is practised-developed in multidisciplinary laboratories which claim to be scientific. (ECHR, 1978) Rejali points out that at best this is also sourced from the perceived humanism and polyvalent use of technology. Pointing to the general public value in electricitybased technologies as an example, Rejali argues that any ill-conceived use, say as constituting a torture method, is faced with a 'civic doubt' as to whether such a technology can be as harmful given its benefits to humanity (2003).

Relatedly, revelations on the use of music as torture (its coerced listening (loud or otherwise), playing, singing or dancing) by the United States in places such as Guantánamo Bay promptly spawned a debate amongst academics and musicians alike. Music's use as therapy renders it difficult to think of its use as torture. Spielmann, a past president of the European Court of Human Rights, has observed that certain uses of music 'can amount to torture, and lyrics can be the vehicle of human rights abuses' (2012, p. 371). Such statements have been seen to herald a change in perceiving non-physical methods (Papaeti, 2013). 
Grant's assessment is that there is nothing intrinsically harmful about music so context is paramount. She prescribes:

Preventing the worst abuses of physical and mental integrity that can be inflicted through music begins with the much more simple act of removing the sheen from musical activities as in some way intrinsically beneficial and morally good. We need to face up to both the possible negative health effects of different musical practices and the long-standing conjunction between music and processes of humiliation and shaming (Grant, 2013, p. 11).

\section{Perceived control: The perversion of 'trust' and 'regulation'}

The complicity of psychology and, perhaps to a lesser extent, psychiatry, intentionally or not, in lending their expertise to state intelligence apparatuses, from the beginnings of the Cold War to the 'War on Terror', is widely accepted in the literature (Physicians for Human Rights, 2005; Pope \& Gutheil, 2009; Soldz, 2011). It is important to recognise the psychology underpinning the psychological techniques of torture and warfare, which has been well-documented elsewhere (Lavik, 1994; McCoy, 2012; Suedfeld, 1990).

Soldz has, for instance, illustrated in some detail the role of psychologists at Guantánamo Bay, in designing the environment to disrupt cohesion and communication among detainees and to foster dependence and compliance instead, and also controlling the minutiae of interrogations to the point of prescribing the limited provision of toilet paper to one detainee (2010). Yet, to the American public, the role of mental health professionals were represented here as ensuring that the pain threshold was contained to a level below that of torture (American Psychological Association, 2005, p. 2). Trust in science was co-opted in order to appease public and institutional consciences. The wheeling out of the phrase 'safe, effective, legal, and ethical' by the Bush Administration was symbolic in manipulating the perception of torture:

... into an expert activity with "scientific techniques" and other accoutrements of professionalism provided advantages to the torturers, conscious and unconscious. The pseudo-scientific façade Jessen and Mitchell developed for the military created a fig-leaf of cover that the torture was not the primitive and sadistic behaviour it really was. It also gave senior military personnel a chance to escape accountability by turning torture over to "the docs"." The Justice Department in effect created a "safe harbour" for interrogators. If a psychologist was involved in the interrogation, by the mere fact of the psychologist's involvement, the "enhanced interrogation" was per se "safe, effective, legal, and ethical". There was no requirement that the psychologist even do anything of a protective nature. His or her very presence, by executive definition, meant that the enhanced interrogation was "safe, effective, legal, and ethical". (Welch, 2010, p. 6)

For Kalbeitzer, the coerciveness of interrogations, as designed by psychologists, was as simple as 'designing the room in such a way as to create an intimidating atmosphere' (Kalbeitzer, 2009). Such tailoring took into account the individual vulnerabilities of the subject. Başoğlu also provides a comprehensive account of the centrality of 'learned helplessness' in CIA's design of its torture regime (Reyes \& Başoğlu, 2017).

For what it is worth, the US Senate 
confirmed that the CIA conducted no 'significant research to identify effective interrogation practices, such as conferring with experienced US military or law enforcement interrogators, or with the intelligence, military, or law enforcements services of other countries with experience in counterterrorism and the interrogation of terrorist suspects' (US Senate Select Committee on Intelligence, 2014, p. 20).

Observing this, O'Mara has deployed the term 'cargo cult science' to refer to such 'use of the language and even behaviours that bear some resemblance to science but critically without the scientific method and the intellectual commitments that follow from the adoption of the scientific method' (2015, p. 30). Similarly, McCoy has also explored the nexus between science and impunity, and the means by which science sanitises and assists in emboldening and legitimating psychological methods of torture, where he states:

The language of science can make psychological torture seem like a series of carefully controlled procedures, sanctioned by rational experts who have the aura of authority that comes with knowledge and credentials (McCoy, 2012, p. 24).

As a side note, McCoy's work on the CIA's development and propagation of psychological methods of torture extensively explores the relationship between impunity, history and public forgetting. The fragility of collective memory means that publicised cases of psychological torture are also susceptible to contestation and manipulation by media and the state, which, according to McCoy, 'tear at the threads of collective memory, making each exposé seem isolated, anecdotal, and ultimately insignificant' (McCoy, 2012a, p. 38). He goes on to underscore the power of history in diffusing efforts at prosecution and prevention.

As a belated point of qualification, one must bear in mind that as much as Rejali alludes to the unacknowledged malleability of technology towards different ends, one must also refrain from holding science to be 'purely truth-seeking' and devoid of values. Moreover, Evans and Morgan militate against torture as conventionally 'unrestrainedly savage', instead depicting it as having long been cruel yet controlled, a 'carefully-regulated practice' (1998, p. 58).

\section{Humiliation:Torture or inhuman and degrading treatment?}

Back-tracking to powerlessness, fear and uncertainty, the relational dynamics, or the power imbalance, between the perpetrator and the victim, particularly with the use of psychological methods must also be considered. Whilst it is not exclusive to psychological torture, it may be argued that its significance is distinct when compared to the use of physical methods. For Pérez-Sales, torture arises where, upon this background of 'powerlessness and suppression', there occurs a violation of dignity and autonomy (2017, pp. 84-85, 261). When the phenomenology of torture is surveyed further, we can see that the torturer demonstrates his power to exhaust, disorient, create dependency, create fear and humiliate his victim (Hauff, 1994, p. 21). Such a violation may also involve self-betrayal, where a victim for instance is forced in the circumstances to do something to acknowledge their absolute helplessness and submission. Doerr-Zegers, speaking from experience on treating Chilean torture victims, states that the 'psychological component of torture becomes a kind of total theatre, a constructed unreality of lies and inversion, in a plot that ends inexorably with the victim's self-betrayal and 
destruction' (McCoy, 2006, p. 10).

The notion of humiliation readily springs to mind here, which is conventionally associated with cruel, inhuman and degrading treatment, and more specifically with degrading treatment (Ireland v. United Kingdom, \$167). Yet, as shall be discussed below, psychologicallyinformed systems of torture, such as those operated by the CIA, feature humiliation as a part of an overall method as a means of breaking the will and extracting information. It is upon this background that Nowak as UNSRT unearthed the centrality of 'powerlessness' to torture: as the most serious violation of the human right to personal integrity and dignity, presupposes a situation of powerlessness of the victim which usually means deprivation of personal liberty or a similar situation of direct factual power and control by one person over another. ... A thorough analysis of the travaux préparatoires of Art 1 and 16 CAT as well as a systematic interpretation of both provisions in light of the practice of the Committee against Torture has led me to the conclusion that the decisive criteria for distinguishing torture from CIDT is not, as argued by the European Court of Human Rights and many scholars, the intensity of the pain or suffering inflicted, but the purpose of the conduct and the powerlessness of the victim. (Nowak \& McArthur, 2006, p. 150; 2008, p. 76; see also Nowak 2006, p. 832; Sifris, 2013)

This is also central for Manderson who sees the 'experience of absolute powerlessness that reduces the victim, in their own eyes as well as their torturer's, to an animal, a body without will or dignity of any kind ... the destruction of identity' (Manderson, 2005, p. 640). Applying this conceptualisation in his assessment of the detainees at
Guantánamo Bay, it was pointed out that: Treatment aimed at humiliating victims may amount to degrading treatment or punishment, even without intensive pain or suffering. It is difficult to assess in abstracto whether this is the case with regard to acts such as the removal of clothes. However, stripping detainees naked, particularly in the presence of women and taking into account cultural sensitivities, can in individual cases cause extreme psychological pressure and can amount to degrading treatment, or even torture. The same holds true for the use of dogs, especially if it is clear that an individual phobia exists. (UN Commission on Human Rights, 2006, \$51).

Başoğlu, Livanou \& Crnobaric, in their oftcited study, conclude that stress indicators of psychological methods including humiliation are similarly severe when compared to physical methods. They posit this as follows:

Ill treatment during captivity, such as psychological manipulations, humiliating treatment, and forced stress positions, does not seem to be substantially different from physical torture in terms of the severity of mental suffering they cause, the underlying mechanism of traumatic stress, and their long-term psychological outcome. Thus, these procedures do amount to torture, thereby lending support to their prohibition by international law. (Başoğlu, Livanou \& Crnobaric, 2007)

This brings into question the feasibility of equating humiliation with the lesser category of inhuman and degrading treatment as most adjudicatory bodies continue to do. It must be said that, whether assumed or dismissed, explicit mention of 'powerlessness' in the work of relevant human rights bodies and 
international law is negligible. Given its centrality, techniques of humiliation that seek to achieve a sense of powerlessness in the victim and the victim's family, and are all too often found to amount to be less severe than torture, need to be seriously reconsidered, given the material differences between the consequences that flow from it, and any underestimation of pain and suffering addressed.

Whilst it is accepted that the particular stigma attached to torture must remain reserved for the most atrocious instances of ill-treatment, the use of powerlessness firms up an opening for ill-treatment to be treatment that is not simply physically brutal. Yet, the resort to severity in differentiating between torture and CIDT has also been increasingly critiqued and abandoned. In Keenan $v$ United Kingdom (2001), the European Court stated that while 'it is true that the severity of suffering, physical or mental, attributable to a particular measure has been a significant consideration in many of the cases decided by the Court under Article 3 of the ECHR, there are circumstances where proof of the actual effect on the person may not be a major factor' $(\$ 113)$. Coupling this with the Selmouni ruling, for the European Court, 'the level of pain inflicted is increasingly a less determinate factor, as acts it once considered only "inhuman" could now rise to the level of torture, depending on the context and purpose for which physical force is employed' (Evans, 2002, p. 373; Selmouni v. France, 1999).

A brief note on purpose under the UNCAT definition is warranted. It is widely interpreted to be inclusive of 'such purposes as' obtaining information or a confession, punishment, intimidation and coercion or discrimination and that it is, therefore, not exhaustive. Yet, there remains a dearth of analysis here when compared to the depth of discussion on other constitutive elements also found therein such as severity of pain and suffering and official capacity. During the drafting process, it seems that the United Kingdom's proposal to include 'gratuitous torture', conceivably meaning torture without purpose or for self-gratification, was not adopted (Nowak \& McArthur, 2008, p. 75). As pointed out by Burgers and Danelius, purposes explicitly stated in the definition are based on state interest (1988, pp. 118119). This may mean that acts intended to humiliate or debase, those arguably closer to gratuitous, do not fall within the category of state interest, and therefore do not amount to torture. That said, even where private sadism predominates, there is 'usually an element of punishment or intimidation' sufficient to satisfy the purposive element under Article 1 (Burgers \& Danelius, 1988, p. 119). Conversely, Article 2 of the InterAmerican Convention against Torture, whilst listing similar purposes, includes 'for any other purpose', hence not proscribing purposes to ones based on state interest.

'Enhanced Interrogation Techniques' (EITS) and the 'Five Methods'

Despite experience disproving the efficacy of coercive tools in eliciting reliable information, the context of interrogation poses a fertile ground for the infliction of torture (Costanzo \& Gerrity, 2009). This is front and centre of UNCAT Article 1's purposive element. Yet, much in the vein of psychological methods of torture, abusive interrogations have not been adequately and explicitly proscribed by international law. In remedying this, by calling for a protocol for non-coercive interviewing, the UNSRT (Mendez) recently stated that:

Torture and ill-treatment harm those areas of the brain associated with 
memory, mood and general cognitive function. Depending on their severity, chronicity and type, associated stressors typically impair encoding, consolidation and retrieval of memories, especially where practices such as repeated suffocation, extended sleep deprivation and caloric restriction are used in combination. Such practices weaken, disorient and confuse subjects, distort their sense of time and render them prone to fabricate memories, even if they are otherwise willing to answer questions. They are also detrimental to the establishment of trust and rapport, and compromise the interviewer's ability to understand a person's values, motivations and knowledge - elements required for a successful interview. (UNSRT, 2016, \$18) Accusatorial, protracted or suggestive interviews overlayed with threats, manipulation and coercion are underscored as unethical, and depending on their 'degree, severity, chronicity and type, undue psychological pressure and manipulative practices' may be ill-treatment (UNSRT, $2016, \$ 44)$. At the very least, one must accept the view of the CAT that 'moderate physical pressure', even when viewed as a 'lawful' mode of interrogation by a state (i.e. Israel), is 'completely unacceptable' as it creates conditions leading to the risk of torture or CIDT (CAT, 1994, p. 10).

Undoubtedly, the gravest contemporary regime of psychological torture, to be publicised at least, has been the United States' abuses of prisoners, by the later disavowed use of 'enhanced interrogation techniques', in various 'black-sites' around the world and notoriously in Abu Ghraib and Guantánamo Bay. In their seminal report 'Break Them Down', Physicians for Human Rights (PHR) lists the employed techniques as including: 'sensory deprivation, isolation, sleep deprivation, forced nudity, the use of military working dogs to instil fear, cultural and sexual humiliation, mock executions, and the threat of violence or death toward detainees or their loved ones' (PHR, 2006, p. 1).

Herman underscores that such 'techniques of establishing control over another person are based upon systematic, repetitive infliction of psychological trauma' (Herman, 2015, p. 69). Moreover, it is in the context of 'highly controlled detention and interrogation environment used to exploit helplessness and vulnerability' engendering the 'denial of autonomy and dependency on interrogators' that such techniques must be viewed (Physicians for Human Rights \& Human Rights First, 2007, p. 6). Similarly, this system has been described as 'ambiguous almost by design' and the 'product of deliberate attempts to engineer tactics that provoke subtle forms of pain, relying on technological, psychological, and pharmacological innovations that maximize the pain or discomfort of the detainee's experience while leaving minimal perceptible evidence of brutality' (McDonnell, Nordgren \& Loewenstein, 2011).

Further on the point of 'design', it is axiomatic to say that trauma can be 'culture-bound' and can differentiate across individuals as the 'meaning of torture and trauma is shaped by social support and religious, cultural and political beliefs' (Physicians for Human Rights \& Human Rights First, 2007, p. 7). Another primary point of discussion has been the exploitation of cultural sensitivities of Arab men regarding sexual taboos (e.g. forced nakedness, contact with a woman) and other phobias (e.g. relating to dogs), based on a text called The Arab Mind by Patai from 2002.

Surveying the mentioned regimes of 
psychological torture, Reyes concludes that 'accumulation of methods' together with 'unpredictability and uncontrollability' (an aggravating feature similar to 'powerlessness') are distinct features here (Reyes, 2007, p. 591). In the same vein, Başoğlu posits that the 'most deleterious consequences stem from uncontrollable aversive events that are also unpredictable' (Başoğlu \& Mineka, 1992, p. 199).

The cumulative or combined nature of these techniques warrants some expansion. Contextually, some legitimate interrogatory methods which may seem 'minor' or 'innocuous' at first glance 'become coercive if used over prolonged lengths of time' (Reyes, 2007, p. 599). That is not to say that this is exclusive to or necessary for psychological torture. Also, isolated instances of methods such as mock executions, death threats or forcefully witnessing torture have been found to amount to torture. The thesis here rather is that such seemingly legitimate or innocuous means 'form a system deliberately designed to wear and break down, and ultimately also to disrupt the senses and personality' (Reyes, 2007, p. 599). In its latest report to the United States, the CAT explicitly recommended that uses of sensory deprivation and sleep deprivation at Guantánamo Bay were violations of the UNCAT and should be abolished (CAT, 2014, \$17). The UNSRT has similarly assessed that "jurisprudence of both international and regional human rights mechanisms is unanimous in stating that such methods violate the prohibition of torture and ill-treatment' (UNSRT, 2004, \$17).

Furthermore, the UNSRT has also seen it necessary to explicitly point out that 'the simultaneous use of these techniques is even more likely to amount to torture' (UN Commission on Human Rights, 2006, §52). During his examination of 'enhanced interrogation techniques' as UNSRT, Rodley pointed out that ' $[\mathrm{e}] \mathrm{ach}$ of these measures on its own may not provoke severe pain or suffering' but may do so in combination 'applied on a protracted basis of, say, several hours' (UNSRT, 1997, \$121). Therefore, he considered a certain degree of combining methods or their accumulation and duration as requisite before the severity threshold became relevant. Sleep deprivation may also prove an apt case to illustrate the cumulative, as opposed to inherent, dynamics here. In its criticism of Israel, the CAT did not categorically state that sleep deprivation, in all cases, amounted to torture but detailed certain durations over specific periods that did (CAT, 1998, \$24).

Two European Court of Human Rights cases of Al Nashiri v. Poland (2014) and Husayn (Zubaydah) v. Poland (2014) where 'EITs' were found as having been used in CIA black-sites in Poland make for enlightening reading here. In $\mathrm{Al}$ Nashiri, the victim was subjected to two mock executions (one with a power drill), stress positions and 'EITs'. The Court characterised these techniques as 'deliberate inhuman treatment causing very serious and cruel suffering' amounting to torture under Article 3. In its assessment, the Court stated all the measures were applied in a:

premeditated and organised manner, on the basis of a formalised, clinical procedure, setting out a "wide range of legally sanctioned techniques" and specifically designed to elicit information or confessions or to obtain intelligence from captured terrorist suspects. Those-explicitly declared-aims were, most notably, "to psychologically 'dislocate' the detainee, maximize his feeling of vulnerability and helplessness, and reduce or eliminate his will to resist ... efforts to obtain critical 
intelligence"; "to persuade High-Value Detainees to provide threat information and terrorist intelligence in a timely manner"; "to create a state of learned helplessness and dependence"; and their underlying concept was "using both physical and psychological pressures in a comprehensive, systematic and cumulative manner to influence [a High-Value Detainee's] behaviour, to overcome a detainee's resistance posture". (\$S 515-516)

Husayn (Zubaydah) v. Poland involved another CIA detainee who had been subjected to the 'EITs', and at 'least 83 waterboard sessions in a single month', before being implicitly threatened with such a method again if he failed to comply. In its assessment, the Court observed:

that this permanent state of anxiety caused by a complete uncertainty about his fate in the hands of the CIA and a total dependence of his survival on the provision of information during the "debriefing" interviews must have significantly exacerbated his already very intense suffering arising from the application of the "standard" methods of treatment and detention in the exceptionally harsh conditions. ( $(509)$

A clear antecedent to this system was the 'five techniques' as used by the British Military firstly in Northern Ireland, during the Troubles, on individuals suspected to be involved with the Irish Republican Army (IRA). It consisted of:

(a) wall-standing: forcing the detainees to remain for periods of some hours in a "stress position", described by those who underwent it as being "spreadeagled against the wall, with their fingers put high above the head against the wall, the legs spread apart and the feet back, causing them to stand on their toes with the weight of the body mainly on the fingers"; (b) hooding: putting a black or navy coloured bag over the detainees' heads and, at least initially, keeping it there all the time except during interrogation; (c) subjection to noise: pending their interrogations, holding the detainees in a room where there was a continuous loud and hissing noise; (d) deprivation of sleep: pending their interrogations, depriving the detainees of sleep; (e) deprivation of food and drink: subjecting the detainees to a reduced diet during their stay at the centre and pending interrogations. ( $\$ 96)$

When considering these methods, the (now defunct) European Commission of Human Rights, focusing on the combined psychological impacts, found that the five techniques constituted torture on the grounds of the intensity directly affects the personality: physically and mentally [and that] the systematic application of the techniques for the purpose of inducing a person to give information shows a clear resemblance to those methods of systematic torture which have been known over the ages... a modern system of torture falling into the same category as those systems... applied in previous times as a means of obtaining information and confessions. (ECommHR, 1976: Ireland v. United Kingdom, (512)

When it progressed to the European Court of Human Rights however, it disagreed and held that the ill-treatment only amounted to cruel inhuman and degrading treatment but not to torture because the necessary severity and intensity of harm that a finding of torture required was not established (according to the de minimis rule). In his dissenting opinion, holding that 
the treatment constituted torture, Judge

Matscher stated that:

the more sophisticated and refined the method, the less acute will be the pain (in the first place physical pain) which it has to cause to achieve its purpose. The modern methods of torture which in their outward aspects differ markedly from the primitive, brutal methods employed in former times are well known. In this sense torture is in no way a higher degree of inhuman treatment. On the contrary, one can envisage forms of brutality which cause much more acute bodily suffering but are not necessarily on that account comprised within the notion of torture.

By some accounts, this was a lost opportunity to stamp out the contemporary uses of such techniques, and has been linked to the reluctance of the Court to find a violation of torture from 1978 to 1996 (Rouillard, 2005, p. 30). Recently reviewing the case upon disclosure of new evidence, the Court decided not to change its original conclusion (Ireland v. the United Kingdom, 5310/71, 20 March 2018) primarily upon the principle of legal certainty. Despite this, in view of its subsequent statements as noted above and in Selmouni v. France (1999, see $\$ 101)$, the Court would now clearly find a regime similar to the five techniques as amounting to torture.

Two decades later, a combination of interrogation methods comparable to the five techniques, for instance, as has been used by Israel on Palestinian prisoners, were documented by the CAT in 1997 to include:

(1) restraining in very painful conditions,

(2) hooding under special conditions, (3) sounding of loud music for prolonged periods, (4) sleep deprivation for prolonged periods, (5) threats, including death threats, (6) violent shaking, and (7) using cold air to chill ...
It assessed this regime as amounting to violations of Articles 1 and 16 of the UNCAT (CAT, 1997, \257). Similarly, the HRC assessed the Israeli use of 'the methods of handcuffing, hooding, shaking and sleep deprivation to have been and continuing as being used as interrogation techniques, either alone or in combination' and that it violated Article 7 of the International Covenant on Civil and Political Rights (HRC, 1998, §19).

\section{Assessment and documentation of psychological methods}

The preceding discussion has attempted to sketch out a number of inter-related elements which obscure a thorough consideration of psychological torture. Compounding these, perhaps more intentional, biases are shortcomings in assessing and documenting allegations of psychological ill-treatment. When compared with the visibility of physical signs of ill-treatment, the relative invisibility of psychological impact can frustrate the processes of evidence-seeking fora.

The 'Break Them Down' report observes the health consequences of psychological methods to be 'extremely destructive' in the short and long term, including:

... memory impairment, reduced capacity to concentrate, somatic complaints such as headache and back pain, hyperarousal, avoidance, irritability, severe depression with vegetative symptoms, nightmares, feelings of shame and humiliation, and posttraumatic stress disorder ... incoherent speech, disorientation, hallucination, irritability, anger, delusions, and sometimes paranoia ... depression, thoughts of suicide and nightmares, memory loss, emotional problems, and are quick to anger and have difficulties maintaining relationships and employment. Based 
on past experience, post traumatic stress disorder is likely to be common. (PHR, 2005, p. 9)

The main issue with respect to the evidentiary dimension is formulating approaches to best understand and document such effects. Most conventional understandings of torture involve the application of physical force; documentation has, therefore, entailed primarily analysing the ensuing physical marks and indicators. Thus, it is imperative to find processes, legal and medical, on which evidentiary corroboration can be formed, specifically sensitive to psychological torture.

Admittedly, specific means of documenting psychological torture remain limited. Psychiatric and psychological sequelae are strong indicators of psychological torture as it is of physical torture. Yet, it is notable that psychological methods are used in combination, either simultaneously or sequentially, to reach a desired effect, as illustrated in the 'five techniques' and 'EITs' (see ICRC, 2007, p. 9). It has been argued that this makes it 'nearly impossible to determine the specific cause of psychopathology shown' (PHR, 2005, p. 70).

\section{Psychological methods of torture and the Istanbul Protocol}

Importantly, the Istanbul Protocol accepts that, since torturers increasingly seek to conceal their crimes, 'the absence of such physical evidence should not be construed to suggest that torture did not occur, since such acts of violence against persons frequently leave no marks or permanent scars.' (OHCHR, $\$ 161$; see also $\$ \$ 159$, $259,260)$. Yet, the unrealistic expectations placed on medical experts who treat and document torture (Freedom from Torture, 2015) coupled with the persisting materialist bias (that is, a preference for the physical) of decision-makers render this declaration, despite increasing awareness, less than fully realised in practice.

Ultimately, however, the Istanbul Protocol conflates the physical and psychological methods and rejects a clear dichotomy as 'artificial' (OHCHR, 2004, \$145). For Reyes, this is understood by the fact that, from a holistic, evidence-based perspective, both physical and psychological torture and effects need to be anticipated. Yet, for him, this somewhat undercuts the stand-alone importance of psychological torture and obfuscates the understanding of the standalone impact of psychological methods (2007, pp. 600-603). Also, for Pérez-Sales, the Istanbul Protocol needs to refine its conception here, and that just because 'the distinction is artificial (i.e. made for epistemological purposes), it does not mean that we shouldn't keep in mind that the ultimate target of torture is the conscious self, and that we should reflect on contemporary torture and the complex ways in which this conscious self is attacked and controlled' (2017, p. 308).

The logic between the act and the effect (without overemphasising the effect) is problematic. It is difficult to frame the question with sufficient specificity; concepts like 'causality', 'link', and 'relation' though useful can prove to be problematic as direct causality rarely exists in medicine. Medical professionals work with percentages and likelihoods in merely identifying where there is corroboration and working with a patient's statement. It is important to refrain from overemphasising the role of individual resilience. Therefore, requiring effect will disadvantage resilient victims. While existence of psychiatric sequelae remains a 'powerful indicator' of psychological torture insofar as 'depression, anxiety and posttraumatic symptoms' can corroborate the treatment 
alleged (Pérez-Sales, 2017, p. 144), such sequelae, however, can never be said to be diagnostic of 'any particular source in the way that a particular scar is diagnostic of a burn or electrical shock' (Jacobs, 2008, p. 169). Moreover, in rejecting legal notions of causality in favour of relativity, Pérez-Sales points out that it is a fallacy to expect science to establish 'an unequivocal causal relationship between certain practices and their consequences in order to determine the limits of torture' (Pérez-Sales, 2017, pp. 274-275).

Difficulties arising out of the invisibility of impact lead the discussion to exploring the purposive alternatives as well as environmental assessments. For PérezSales, evaluating torture environments can be a significant means to document psychological torture. He defines the torture environment as:

... a milieu that creates the conditions for torture ... made up of a group of contextual elements, conditions and practices that obliterate the will and control of the victim, compromising the self. ... In epidemiological terms, any element can be considered part of a torturing environment if it has been identified as likely to increase the relative risk of severe physical or psychological suffering, if it is used within the context of torture or if it is employed with the purpose of inflicting torture. ... Given that methods aren't used alone but as part of a system, the environment they operate in also needs to be holistically assessed. (2017, pp. 285, 330)

In a study conducted by Pérez-Sales et al, Basque prisoners held in incommunicado detention were interviewed at length in order to 'elaborate a prototypical process of detention and ill-treatment which helped to understand the dynamics of an interrogation procedure' (Pérez-Sales, 2016, p. 21). There, the authors underscore that this methodology builds on conventional descriptive and testimonial documentation to encompass a broader epidemiological approach:

The creation of a Torturing Environment requires the interaction of several elements: (a) sensorial and temporal disorientation and confusion of the self- reflecting mind; (b) fear and terror that starts from the outset of detention and remains present throughout; (c) humiliations and attacks on identity that contribute to eroding any sense of control; and, (d) tension and beatings that produce physical and emotional exhaustion. The capacity of the victim for proper understanding, retrieval of memories, judgement and reasoning is progressively undermined. The techniques of emotional manipulation and cognitive distortion used during the interrogation complete the process.

Soon strengthened by validation (see PérezSales, Martínez-Alés, Gonzalez Rubio, p. 2018), the Scale represents a leading tool of documentation with respect to psychological methods.

This is identified by its author as complementing and compatible with the Istanbul Protocol, primarily to bring to the fore, and hence better appreciate, methods of psychological torture. Whilst this is a promising and innovative proposal, it remains to be tested and used more widely. Similarly, explorative studies into the neurobiology of psychological torture also promise to provide corroborative evidence through identifying biological markers (Ojeda, 2008).

Subjectivity and severity: Obfuscation of pain, bias, resilience

Whilst also tied to physical instances of illtreatment, the elements of subjectivity and 
severity feature distinctively with respect to psychological torture. Subjectivity is used here to refer to both specific factors pertaining to individuals claiming to have been subjected to torture as well as the unfounded bias of decision-makers assessing 'severe pain' to require the physical and downplaying the psychological.

In her seminal work, Scarry explains that the 'unshareability' of pain underscores the significance of considering subjectivity in assessing torture claims (Scarry, 1986). Some commentators have argued that this 'unshareability' is constant, for it is seen to be based on human impulses to be self-serving in our assessments (in using ends-based reasoning) and having a hotcold empathy (not being able to register pain through witnessing or hearing about it) (Nordgren, McDonnell \& Loewenstein, 2011). Tied to this, the concept of severity has been critiqued by prominent commentators as being 'vague and open to interpretation', 'not susceptible to precise gradation' and 'virtually impossible' based on these reasons.

Conversely, it must be pointed out that medical professionals diagnose and administer relief when treating varying levels of pain, physical and psychological, on a daily basis. It is instructive to note that the difficulties present with respect to subjectivity have also been used as an excuse to conclude 'pain is a subjective experience and there is no way to objectively quantify it' (Stover, Koenig \& Fletcher, 2017, p. 392). Accordingly, theoretical problematising, as outlined below, must be approached with some degree of caution.

The methods at hand challenge 'reliance on a solely objective analysis of suffering, due to the difficulties in measuring intangible psychological injuries' (Yarwood, 2008, p. 336). Partially arising out of this, conventional understandings of severity also reveal a materialist or physical bias, 'that the physical is more real than the mental' (Luban \& Shue, 2011 , p. 823). Reyes compares the relative ease of documenting the physical with the psychological in the following passage:

Physical forms of pain and suffering are more readily understood than psychological forms, although physical suffering may also be hard to quantify and measure objectively - defining severe pain and suffering involves an assessment of gravity that is difficult to make, as these notions are highly subjective and may depend on a variety of factors, such as the age, gender, health, education, cultural background or religious conviction of the victim. (Reyes, 2007, p. 593)

Attempts, by notorious figures in the Bush Administration, to obscure the conceptualisation of torture have entailed the unfounded claims such as 'mental suffering is often transitory, causing no lasting harm,' (US Senate Committee on Foreign Relations, 1990, p. 17) or that torture is 'broken bones, electric shocks to genitalia ... pulling your teeth out with pliers ... cutting off a limb ... Is waterboarding at the same level? I'd say probably not.' Similarly, it has been suggested that psychological methods such as solitary confinement or sleep deprivation are more readily dismissed as we all experience and tolerate small doses of solitude and sleeplessness in our daily lives, without ever understanding the impact of the extremities (McDonnell, Nordgren \& Loewenstein, 2011). Commenting on this mentality, O'Mara assesses this as being: the all-too-common mistake of consulting the contents of his consciousness to define torture-not statute law, not international treaties, not medical authorities, not the scholarly literature. This leaves us with a 
problem: when we think of torture, our thinking is deeply colored by images of medieval cruelty: the rending of flesh, the breaking of bones, and pain made visible through scar and scream. We do not think of techniques that leave no visible record of their presence, techniques that manipulate the metabolic and psychopathological extremes of body, brain, and behaviour, and which are, by any reasonable standard, torture. (O’Mara, 2015, p. 11; see also Posner, 2004, pp. 291-292)

This brings into focus the discomfort versus ill-treatment debate. Pérez-Sales admits that it is 'difficult to know why some techniques [such as the use of music] and not others would qualify as "uncomfortable"; the distinction between "torture" and "discomfort" seems to be merely semantic' (2017, p. 328). Interrogations, after all, regularly exploit specific vulnerabilities of an individual in making them uncomfortable. What is more, recognising that a vast proportion of torture victims prove resilient (as high as $60 \%$ by one measure (PérezSales, 2017, p. 144), distinguishing the impact of psychological torture as opposed to discomfort is made additionally difficult (Başoğlu, 2009, p. 142).

Compounding this, psychological torture is defined as anything but torture by those partaking in its infliction or legitimisation: the torturer defines it as a technologicallycontrolled method designed to fall short of severe harm (Sveaass, 2008, p. 304); politicians have narrowly defined it in times of national security issues as 'enhanced interrogation' (McDonnell, Nordgren \& Loewenstein, 2011, p. 94; see also Luban \& Shue, 2011, pp. 826-827); and, some domestic courts have avoided attributing torture to state authorities, if possible (see PCATI v. Israel, 1999).
Biased preconceptions against defining psychological methods as torture are infamously illustrated by the European Court of Human Rights' decision in Ireland $v$ United Kingdom as the five techniques were found not to 'occasion suffering of the particular intensity and cruelty implied by the word torture'. This equated torture with 'acts of extreme barbarity' and not the 'systematically researched and applied subtle techniques of psychological manipulation which nullify the human will' (Spjut, 1979, p. 271).

This has been remedied, fully cognisant of subtle mechanisms of torture, in the definition of the Inter-American Convention to Prevent and Punish Torture which reads:

Torture shall also be understood to be the use of methods upon a person intended to obliterate the personality of the victim or to diminish his physical or mental capacities, even if they do not cause physical pain or mental anguish. (OAS, 1985, Article 2)

Here: i. pain is not required; ii. severity of suffering is not required as the emphasis is on methods not consequences; iii. purpose is to 'obliterate the personality of the victim' or to 'diminish his mental capacities' (Pérez-Sales, 2017, p. 3). As the measure of severity is side-stepped, a purposive measure of psychological torture, one more conducive to capture the phenomenon, can be applied. This also brings into play a number of elements Pérez-Sales deems to be especially significant to the psychological torture context, including: $i$. the relationship pattern between torturer and tortured; ii. circumstances of the torturing system (political persecution, law enforcement procedure, etc.); iii. whether techniques target identity; and, iv. the severity of each experience from both an objective and subjective point of view. 
Taking into account the conceivably infinite iterations of psychological methods as designed to target an individual's particular values, it can be argued that the complexity of subjectivity surpasses that of physical pain. Interpersonal elements, such as the increased susceptibility to psychological harm for those with a supportive familial environment ('securely attached') on the background of their trust in humanity and benevolent worldview (Kanninen, Punamäki, Qouta, 2003), and the use of an individual's severe phobia of the dark during coercive interrogations have been but two aspects documented in the literature (Lewis, 2005).

A comparable complexity is confirmed in medical literature on trauma, as there 'are infinite ways of reacting and psychologically processing the same event' (Pérez-Sales, 2017, pp. 129-133). PérezSales points out that DSM's definition of trauma has been refined from 'an extensional definition ("extraordinary events"), to a subjective consequentialist definition ("overwhelming emotions"), and now to an objective consequentialist definition ("threat")' (2017, pp. 133-134). To mirror this development, torture would exclude the objective severity test, avoid an extensional definition, and consider 'exposure to threat as the core feature'.

How does, for instance, a male decision-maker fully appreciate the impact of sexual humiliation of a woman? (Arcel, 2003) How does one articulate witnessing the regular desecration of the Koran or being prevented from praying? (Khan, 2010; McCoy, 2012) How can a decisionmaker gauge the anguish of a third party such as a relative or witness who vicariously experiences the impact of torture? The questions abound but not for a lack of interest in the answers.

\section{Conclusions: Room for reflection and research}

In light of the difficulties outlined in this paper, international and national bodies need to better incorporate a medical understanding, particularly a psychological one, that is workable within the severity paradigm. Questions arising from some of the key literature in this review include: How can the law better reflect the phenomenon of psychological torture through the prism of psychology, in terms of quantifying severity, duration and effects? How do we then achieve a confluence between the two fields with respect to this issue? To quantify level of pain, medical professionals resort to notions of 'duration', 'frequency', and 'intensity'. Other notions such as 'dignity', 'agency', and 'fear' perhaps need to be factored in more strongly.

At the very least, these must be understood and engaged with by the law. Related understandings also need to be accepted. The three decades of research, some of which is outlined here, does not support the equation that the magnitude of applied stress will result in a corresponding magnitude of impact. That is, little stress could lead to a significant impact, and great stress to little impact. There are many variables (e.g. age, culture, health) to render general rules unsuitable such as a minimum six hours of sleep for every 24 , or that certain symptoms are exclusively linked to certain acts.

Given the shortcomings in the law, there exists enough space to develop and sharpen standards, both regionally and internationally. Identifying institutional, cultural and practical shortcomings of professionals, namely police, lawyers, judges, psychologists and doctors etc., and their related institutions in this area will be important in developing the necessary tools of training and documentation. 
Relatedly, it has been pointed out that what is required is to fix a common understanding of psychological torture which is defined based on strong research, which international and national bodies, recognising its value, would adopt and operationalise in their work. Specifically, they need to clarify and expand on the notion of 'mental suffering' as part of the definition of torture. To that end, two broad sets of issues can be identified as those that impede this understanding, as follows:

i. How do victims' prior psychological states (broader than the notion of 'condition' to include personal values and other subjective qualities) influence assessments of psychological torture's impact? Can we, and if so how do we, differentiate the trauma an individual is subjected to, due to their mere interaction with criminal justice apparatus and processes, from anything that amounts to ill-treatment of any severity (torture or not)? Taking victims as one finds them is a basic principle of civil and criminal law. At the very least, it is not a mitigatory factor in international law. Accordingly, factoring in a victim's 'predisposition to suffer', or conversely 'resilience', raises complicated issues.

ii. How do we overcome the existing hierarchies (where some physical torture methods enjoy quicker recognition than, for example, humiliation)? Is a western psychological understanding of trauma, particularly with respect to psychological torture, applicable and transferrable to non-western jurisdictions? If not, what are the issues arising for the recognition of psychological torture in those jurisdictions? What are the factors, such as common misconceptions, professionals demonstrate in contributing to and/or dealing with the prevalence of psychological torture? What is the level of awareness that psychologically coercive acts can amount to torture? How many domestic criminal codes fail to recognise the mental element? What training tools can be developed to complement or re-work the existing deficiencies in knowledge and process?

Outstanding questions necessitating further reflection and research, arising out of this review, point to improved dialogue between of psychology and law, developing and sharpening standards with respect to documentation and, in turn, prevention, prosecution and adjudication.

\section{References}

American Psychological Association. (2005). Report of the American Psychological Association Presidential Task Force on Psychological Ethics and National Security. http://dx.doi.org/10.1037/ e419822005-001

Arcel, L. T. (2003). Inhuman and degrading treatment of women: psychological consequences. In: Kjærum, M., Thelle, H., Xia Yong \& Bi Xiao Quing (eds.). (2003). How to eradicate torture (pp. 951-984). Beijing: Social Sciences Documentation Publishing House.

Başoğlu, M. (ed). (2017). Torture and Its Definition in International Law: An Interdisciplinary Approach. New York: Oxford University Press. https://doi. org/10.1093/med/9780199374625.001.0001

Başoğlu, M. (2009). A multivariate contextual analysis of torture and cruel, inhuman, and degrading treatments: implications for an evidencebased definition of torture. American fournal of Orthopsychiatry, 79(2), 135-45. https://doi. org/10.1037/a0015681

Başoğlu, M., Livanou, M., \& Crnobaric, C. (2007). Torture vs other cruel, inhuman, and degrading treatment. Archives of General Psychiatry, 64, 27785. https://doi.org/10.1001/archpsyc.64.3.277

Başoğlu, M., \& Mineka, S. (1992). The role of uncontrollable and impredictable stress in postraumatic stress responses in torture survivors. In: Başoğlu M. (Ed.). (1992). Torture and its consequences: Current treatment approaches (pp. 182-225).New York: Cambridge University Press.

Burgers, J.H, \& Danelius, H. (1988). The United Nations Convention against Torture: $A$ Handbook on the Convention Against Torture and Other Cruel, Inhu- 
man or Degrading Treatment or Punishment. Dordrecht-Boston-London: Martinus Nijhoff.

Costanzo, M.A. \& Gerrity, E. (2009). The effects and effectiveness of using torture as an interrogation device: using research to inform the policy debate. Social Issues and Policy Review, 3(1), 179-210. https://doi.org/10.1111/j.17512409.2009.01014.x

Crampton, D. (2013). What indicators exist, or may exist, to determine whether a violation of the prohibition of torture, inhuman or degrading treatment or punishment has occurred on the basis of psychological maltreatment, and whether it amounts to psychological torture. LLM Dissertation. School of Law. University of Essex (on file with author).

ECHR. (1978). Ireland v. United Kingdom, 5310/71, 19 January 1978.

ECHR. (2018). Ireland v. United Kingdom, 5310/71, 20 March 2018.

ECHR. (2001). Keenan v. United Kingdom, 27229/95, 3 April 2001.

ECHR. (2014). Al Nashiri v. Poland, 28761/11, 24 July 2014.

ECHR. (2014). Husayn (Zubaydah) v. Poland, 7511/13, 24 July 2014.

ECHR. (1999). Selmouni v. France, 25803/94, 29 July 1999.

ECommHR. (1976). Ireland v. United Kingdom, European, Yearbook of the European Convention on Human Rights, 19.

Evans, M.D. (2002). 'Getting to Grips with Torture'. International and Comparative Law Quarterly 51(2), 365-383.. https://doi.org/10.1093/ iclq/51.2.365

Evans, M.D. \& Morgan, R. (1998). Preventing Torture: A Study of the European Convention for the Prevention of Torture and Inhuman or Degrading Treatment or Punishment. New York : Oxford University Press.

Farber, I.E., Harlow, H.F. \& West, L.J. (1957). Brainwashing, conditioning, and DDD (debility, dependency, and dread). Sociometry, 20, 271-285. https://doi.org/10.2307/2785980

Freedom from Torture. (2015). "Proving” Torture: An ever-rising bar for medical evidence? Conference October 2015.

Ginbar, Y. (2017). Making Rights Sense of the Torture Definition. In: Başoğlu, M. (ed.). (2017). Torture and Its Definition in International Law: An Interdisciplinary Approach (pp. 273-314). New York: Oxford University Press.

Grant, M. J. (2013). The illogical logic of music torture. Torture, 23(2), 4-13.

Hauff, E. (1994). The Phenomenology of Torture. In Lavik, N.J., Nygaard, N., Sveaass \& E. Fannemel (eds.). (1994). Pain and Survival: Human Rights
Violations in Mental Health. (pp.19-28). Oslo: Scandinavian University Press.

Herman, J. (2015). Trauma and Recovery: The Aftermath of Violence - from Domestic Abuse to Political Terror. New York: Basic Books.

High Court of Israel. (1999). Public Committee Against Torture in Israel v. Israel H.C. 5100/94.

Inter-Am.C.H.R, Raquel Martí de Mejía v. Perú, Case 10.970, Report No. 5/96, OEA/Ser.L/V/II.91

Doc. 7 at 157 (1996)

International Committee of the Red Cross. (2007). Report on the Treatment of Fourteen "High Value Detainees" in CIA Custody.

Jacobs, U. (2008). Documenting the neurobiology of psychological torture: conceptual and neuropsychological observations. In: Ojeda, A. E. (Ed.). (2008) The trauma of psychological torture (pp. 163-172). Connecticut and London: Praeger.

Kalbeitzer, R. (2009). Psychologists and Interrogations: Ethical Dilemmas in Times of War. Ethics and Behaviour, 19(2), 156-168. https://doi. org/10.1080/10508420902772793

Kanninen, K., Punamäki, R-L. \& Qouta, S. (2003). Personality and Trauma: Adult Attachment and Posttraumatic Distress Among Former Political Prisoners. Peace and Conflict: Fournal of Peace Psychology, 9(2), 97-126. https://doi.org/10.1207/ s15327949pac0902_01

Khan, A. (2010). Faith-Based Torture. Global Dialogue, 12(1-2). https://doi.org/10.2139/ ssrn. 1504754

Lewis, N. A. (2005). Interrogators cite doctors' aid at Guantánamo. New York Times, 24 June 2005.

Luban, D., \& Shue, H. (2012). Mental torture: A critique of erasures in U.S. law. The Georgetown Law fournal, 100, 823-63. https://doi.org/10.1017/ cbo9781107279698.011

Manderson, D. (2005) Another Modest Proposal. Deakin Law Review, 10(2), 640-653. https://doi. org/10.21153/dlr2005vol10no2art297

McCoy, A. (2006). A Question of Torture: CIA Interrogation, from the Cold War to the War on Terror. New York: Metropolitan Books.

McCoy, A. (2012). Torture and Impunity: the US Doctrine of Coercive Interrogation. Madison: University of Wisconsin Press.

McCoy, A. (2012a). In the Minotaur's Labyrinth: Psychological Torture, Public Forgetting, and Contested History. In: Carlson, J. \& Weber, E. (eds.). (2012). Speaking about Torture (pp. 37-58). New York: Fordham University Press. https://doi. org/10.5422/fordham/9780823242245.003.0003

McDonnell, M., Nordgren, L. F., \& Loewenstein, G. (2011). Torture in the eyes of the beholder: the psychological difficulty of defining torture in 
law and policy. Vanderbilt fournal of Transnational Law, 44, 87-122.

Nordgren, L., McDonnell M., \& Loewenstein G. (2011). What Constitutes Torture? Psychological Impediments to an Objective Evaluation of Enhanced Interrogation Tactics. Psychological Science, 22(5), 689-694. https://doi. org/10.1177/0956797611405679

Nowak, M. \& McArthur E. (2008). United Nations Convention Against Torture: A Commentary. New York: Oxford University Press. https://doi. org/10.1093/law/9780199280001.001.0001

Nowak, M. \& McArthur, E. (2006). The Distinction between Torture and Cruel, Inhuman or Degrading Treatment. Torture, 16(3), 147-151.

Nowak, M. (2006). What Practices Constitute Torture?: US and UN Standards. Human Rights Quarterly, 28(4), 809-841. https://doi. org/10.1353/hrq.2006.0050

O'Mara, S. (2015). Why Torture Doesn't Work: The Neuroscience of Interrogation. Cambridge, MA: Harvard University Press.

Ojeda, A. (ed). (2008). The Trauma of Psychological Torture. Connecticut and London: Praeger.

Organization of American States (OAS). (1985). InterAmerican Convention to Prevent and Punish Torture. 9 December 1985, OAS Treaty Series, No. 67.

Papaeti, A. (2013). Music, Torture, Testimony: Reopening the Case of the Greek Military Junta (1967-1974). In: Grant M.J., Papaeti, A., (eds.). (2013). The world of music: Music and Torture, $M u$ sic and Punishment 2(1). 67-89.

Pérez-Sales, P. (2017). Psychological Torture: Definition, Evaluation and Measurement. London: Routledge. https://doi.org/10.4324/9781315616940

Pérez-Sales, P., et al. (2016). Incommunicado detention and torture in Spain, Part III: 'Five days is enough': the concept of torturing environments. Torture, 26(3), 21-33.

Pérez-Sales, P, Martínez-Alés, G, Gonzalez Rubio, R. (2018). Beyond torture checklists. Reliability and Construct Validity of the Torturing Environment Scale (TES). Conflict and Health (submitted/personal communication).

Pictet, J. (ed.). (1958). The Geneva Conventions of 12 August 1949: Commentary, Vol. IV, Geneva Convention Relative to the Protection of Civilian Persons in Time of War. Geneva: International Committee of the Red Cross.

Physicians for Human Rights. (PHR). (2005). Break them Down: Systematic Use of Psychological Torture by US Forces.

Physicians for Human Rights and Human Rights First. (2007). Leave No Marks: "Enhanced" interrogation techniques and the risk of criminality.
Pope, K.S., Gutheil, T.G. (2009). Psychologists abandon the Nuremberg ethic: Concerns for detainee interrogations. International fournal of Law and Psychiatry, 32, 161-166. https://doi.org/10.1016/j. ijlp.2009.02.005

Posner, R. (2004). Torture, Terrorism and Interrogation. In: Levinson, S. (ed.). (2004). Torture: $A$ Collection (pp.291-298). New York: Oxford University Press.

Rejali, D. (2003). Modern Torture as a Civic Marker: Solving a Global Anxiety with a New Political Technology. Fournal of Human Rights, 2(2), 153-171. https://doi. org/10.1080/1475483032000078152

Rejali, D. (2007). Torture and Democracy. Princeton: Princeton University Press. https://doi. org/10.1515/9781400830879

Reyes, H. \& Başoğlu, M. (2017). Control as a Defining Characteristic of Torture. In Başoğlu, $M$. (2017). Torture and Its Definition in International Law: An Interdisciplinary Approach (pp. 49-59). New York: Oxford University Press.

Reyes, H. (2007). The worst scars are in the mind: psychological torture. International Review of the Red Cross, 89(867), 591-617. https://doi. org/10.1017/s1816383107001300

Rouillard, L-P. (2005). Misinterpreting the Prohibition on Torture Under International Law: The Office of Legal Counsel Memorandum. American University International Law Review, 21(9), 9-41.

Scarry, E. (1986). The Body in Pain: The Making and Unmaking of the World. New York: Oxford University Press.

Sifris, R. (2013). Reproductive Freedom, Torture and International Human Rights: Challenging the Masculinisation of Torture. London: Routledge. https:// doi.org/10.4324/9780203074749

Soldz, S. (2010). Psychologists Defy Torture: The Challenge and the Path Ahead. In: Harris, A. \& Botticelli, S. (eds.). (2010). First do no harm: the paradoxical encounters of psychoanalysis, warmaking, and resistance (pp. 67-106). New York: Routledge. https://doi.org/10.4324/9780203885192

Soldz, S. (2011). Fighting Torture and Psychologist Complicity. Peace Review: A fournal of Social fustice, 23(1), 12-20. https://doi.org/10.1080/104026 59.2011 .548240

Spielmann, D. (2012). Variations on an Original Theme: Music and Human Rights. In: Casadevall, J. (ed.). (2012). Freedom of Expression: Essays in Honour of Nicolas Bratza (pp. 363-381) Oisterwijk: Wolf Legal Publishers.

Spjut, R. (1979). Torture Under the European Convention on Human Rights. American fournal of 
International Law, 73(2), 267-272. doi:10.1017/ S000293000010764X

Stover, E., Koenig, K.A., \& Fletcher, L.E.. (2017).

The Cumulative Effect. In: Başoğlu, M. (2017). Torture and Its Definition in International Law: An Interdisciplinary Approach (pp. 375-407). New York: Oxford University Press.

Suedfeld, P. (ed.). (1990). Psychology and Torture. Washington, DC: Hemisphere Publishing Corp.

Sveaass, N. (1994). The Organized Destruction of Meaning. In: Lavik, N.J., Nygaard, N., Sveaass \& E. Fannemel (eds.). (1994). Pain and Survival: Human Rights Violations in Mental Health (pp. 4365). Oslo: Scandinavian University Press.

Sveaass, N. (2008). Destroying Minds: Psychological Pain and the Crime of Torture. New York City Law Review, 11(2), 303-324.

UN Commission on Human Rights. (2006). Situation of Detainees at Guantánamo Bay. E/ CN.4/2006/120, 27 February 2006.

UN Committee Against Torture. (2006). Conclusions and Recommendations, USA. CAT/C/USA/CO/2, 25 July 2006.

UN Committee Against Torture. (1994). Summary of the 184th Meeting, 12th Session. CAT/C/SR.184.

UN Committee Against Torture. (1997) Report on Israel. A/52/44, 10 September 1997.

UN Committee Against Torture. (1998) Consideration of Report on Israel. CAT/C/SR.336, 20 November 1998.

UN Committee Against Torture. (2014) Conclusions and Recommendations on USA. CAT/C/USA/ $\mathrm{CO} / 3-5$.

UN Human Rights Committee. (1992). CCPR General Comment No. 20: Article 7 (Prohibition of Torture, or Other Cruel, Inhuman or Degrading Treatment or Punishment),10 March 1992.

UN Human Rights Committee. (1998). Concluding Observations on Israel. CCPR/C/79/Add.93.

UN Office of the High Commissioner for Human Rights (OHCHR). (2004). Manual on the Effective Investigation and Documentation of Torture and Other Cruel, Inhuman or Degrading Treatment or Punishment ('Istanbul Protocol'). HR/P/PT/8/Rev.1

UN Special Rapporteur on Torture. (1997). Report. E/CN.4/1997/7, 10 January 1997.

UN Special Rapporteur on Torture. (2004). Report. A/59/324, 1 September 2004.

UN Special Rapporteur on Torture. (2016). Report. A/71/298, 5 August 2016.

US Senate Select Committee on Intelligence. (2014). Committee Study of the Central Intelligence Agency's Detention and Interrogation Program. (With declassification revisions of 3 December 2014).

US Senate Committee on Foreign Relations. (1990).
Convention Against Torture: Hearing Before the S. Comm. on Foreign Relations. 101st Congress 13

Welch, B. (2010). The Torturer's Apprentice: Psychology and Enhanced Interrogations. Global Dialogue, 12(1-2), 1-14.

Yarwood, L. (2008). Defining Torture: The Potential for Abuse. Fournal of the Institute of Fustice $\mathcal{E}$ International Studies, 8(3), 324-351. 